\section{Pest Management in the U.S. Greenhouse and Nursery Indus- try: III. Plant Growth Regulation}

\author{
Jeffrey G Norcini', \\ William G Hudson², \\ Melvin P. Garber ${ }^{3}$, \\ Ronald K. Jones ${ }^{4}$, \\ Ann R. Chase ${ }^{5}$, and \\ Kane Bondari ${ }^{6}$
}

Additional index words. plant growth regulator, ornamentals, floriculture, DIF, pruning, photoperiod, light quality, mechanical brushing

Summary. Growers in the American Association of Nurserymen and the Society of American Horists were queried as to their use of plant growth regulators (PGRs) and nonchemical alternative practices during 1993. Daminozide (B-

${ }^{1}$ Associate professor, University of Florida Research and Education Center, Route 4, Box 4092, Monticello, FL 32344-9304.

${ }^{2}$ Associate professor and extension entomologist, University of Georgia, P.O. Box 1209, Tifton, GA 31793.

${ }^{3}$ Associate professor and extension horticulturist, University of Georgia, P.O. Box 1209, Tifton, GA 31793.

4Professor and extension plant pathologist, North Carolina State University, Raleigh, NC 27695.

${ }^{5}$ Emeritus professor of plant pathology, Central Florida Research and Education Center, University of Florida, Apopka, FL 32703.

${ }^{6}$ Professor, Department of Statistical and Computer Service, Coastal Plain Experiment Station, Tifton GA 31793.

Florida Agricultural Experiment Station journal series no. R-04671.

The cost of publishing this paper was defrayed in part by the payment of page charges. Under postal regulations, this paper therefore must be hereby marked advertisement solely to indicate this fact.
Nine SP) and chlormequat chloride (Cycocel) accounted for $78 \%$ of the total pounds active ingredient and were used by $20 \%$ and $17 \%$ of the respondents, respectively. In contrast, the rooting compounds indolebutyric acid (Dip 'N Grow, Rootone, and Hormoroot) and naphthaleneacetic acid (Dip 'N Grow, and Hormodin I, II, and III) were used by 53\% and $24 \%$ of the respondents, respectively, but combined accounted for less than 3\% of total pounds active ingredient. Pruning/ pinching was used by the greatest number of respondents (82\%) and was the only alternative to PGRs rated as very effective by more than $60 \%$ of the respondents. Use of chemical PGRs and nonchemical alternative practices was influenced by region and firm size. In the northeastern United States, growers reported relatively low use of PGRs (frequency and total pounds) and the lowest use of mechanical brushing as an alternative practice. In contrast, mechanical brushing was used most in the western United States. Large firms (more than $\$ 2$ million in annual sales) reported the greatest use of chemical and nonchemical means of regulating growth.

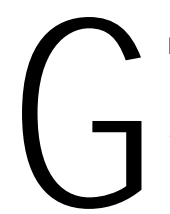
rowth regulation methods have changed periodically over the years in relation to sociological and scientific developments. When the ornamentals industry started in the early 1900 s, most methods were based on cultural manipulation, since few chemical growth regulators were known or used. For example, cultural practices such as bottom heating were emphasized for rooting woody plant cuttings in the early 1930s (Laurie and Chadwick, 1931). Chemicals such as potassium permanganate, acetic acid, sucrose, and boric acid were mentioned as factors that might enhance rooting (Laurieand Chadwick, 1931). The use of synthetic auxins to stimulate rooting started during the 1940s; however, it was not until the late 1950s and 1960 s that many new organic compounds became available and revolutionized the ornamentals industry. Products such as chlormequat chloride (Cycocel) and daminozide (Alar;B-Nine SP) were highly effective and made regulating growth of flowering and ornamental plants cost-effectiveand easier in many cases than the cultural methods previously available (Cathy, 1964). These newer products allowed ahigher-quality, less-expensive product to be distributed throughout the world. During the past 10 years, developments that permitted easier management of humidity, light, and temperature, and computerized irrigation systems have facilitated the integration of cultural and chemical growth regulation methods in the ornamental industry.

Many professionals report observational shifts in use of specific pest control and growth regulation methods, but no comprehensive study on the methods used in the ornamental greenhouse and nursery trade is available. In 1991, SRI International conducted a survey of United States ornamental growers to evaluate the most commonly used products for pest control (SRI International, 1992). They found that PGRs accounted for only $1.2 \%$ (pounds activeingredient) of thechemicals used. The greatest use of PGRs was to control internode elongation and height, improve color, and promote flowering of a few high-profile floricultural crops such as azalea, chrysanthemum, hibiscus, poinsettia, and spathiphyllum. Daminozide (B-Nine SP) and chlormequat chloride (Cycocel) accounted for $76 \%$ and $21 \%$ of the total PGR use, respectively. Rooting compounds accounted for less than $0.2 \%$ of PGR use.

This pape presents the results of a survey on pest control and growth regulation methods used by the nursery and greenhouse industries. It was conducted with the assistance of the American Association of Nurserymen (AAN) and the Society of American Florists (SAF). The following information is presented to improve targeting of new products and services for the ornamentals industry, as well as to evaluate the degree of knowledge, use, and efficacy of the full range of growth regulation methods currently available. Future research, extension, and allied industry efforts must include this type of information if they are to serve the ornamentals industry effectively.

This survey was conducted and data were analyzed as detailed in Garber et al. (1996).

\section{Results and discussion}

Chemical plant growth regulators. The two most commonly used PGRs were rooting compounds- $53 \%$ of the respondents used indolebutyric acid (IBA; Dip 'N Grow, Rootone, and Hormoroot), whereas $24 \%$ used napthal eneacetic acid (NAA; Dip 'N Grow, and Hormodin I, II, and III) (Table 1). However, these two chemicals only accounted for less than $3 \%$ of the total pounds of active ingredient. The other rooting chemical, the potassium salt of IBA, was only used by $2 \%$ of the respondents $(0.1 \%$ of the total pounds active ingredient).

Daminozide was the most frequently used growth retardant (20\% of respondents) and accounted for $54 \%$ of the pounds active ingredient (Table 1). Chlormequat chloride and ancymidol (A-Rest) were used by $17 \%$ and $10 \%$ of the respondents, respectively, but only chlormequat chloride represented a substantial amount of pounds active ingredient ( $24 \%$ of total). Less than $10 \%$ of the respondents used the other PGRs (listed in decreasing order of frequency in Table 1)- paclobutrazol (Bonzi), gibberellic acid 
Table 1. Estimated use of chemical plant growth regulators in the United States greenhouse and nursery industry.

\begin{tabular}{|c|c|c|c|c|}
\hline \multirow[b]{2}{*}{ Plant growth regulator } & \multicolumn{2}{|c|}{ Respondents } & \multicolumn{2}{|c|}{ Estimated total active ingredient } \\
\hline & No. & $\%^{2}$ & $\mathrm{Ib}^{\mathrm{y}}$ & $\%^{x}$ \\
\hline Indolebutyric acid (IBA) & 373 & 53 & 510 & 2 \\
\hline Naphthaleneacetic acid & 167 & 24 & 255 & 1 \\
\hline Daminozide & 139 & 20 & 17677 & 54 \\
\hline Chlormequat chloride & 122 & 17 & 8035 & 24 \\
\hline Ancymidol & 71 & 10 & 8 & $>1$ \\
\hline Paclobutrazol & 67 & 9 & 30 & $>1$ \\
\hline Gibberellic acid & 58 & 8 & 93 & $>1$ \\
\hline Ethephon & 55 & 8 & 1328 & 4 \\
\hline Uniconazole & 32 & 4 & 8 & $>1$ \\
\hline Dikegulac & 24 & 3 & 5269 & 15 \\
\hline Other & 17 & 2 & 39 & $>1$ \\
\hline
\end{tabular}

${ }^{z}$ As a percentage of total respondents $=712$; table in descending order of number respondents.

yEstimated total active ingredient used in the United States for each plant growth regulator.

${ }^{x}$ Pounds of active ingredient for a specific plant growth regulator expressed as the percentage of the total pounds used of all plant growth regulators $=41,305 \mathrm{Ib}$.

(ProGibb, Gibrel; also a component of Promalin), ethephon (Ethrel and Florel), uniconazole (Sumagic), and dikegulac (Atrimmec); benzylaminopurine (Proshear; also a component of Promalin), mefluidide (Embark Trim-Cut), and the potassium salt of IBA, when combined, were only used by $2 \%$ of these respondents (Table 1 ).

The cases above, in which there is a relatively low frequency of use and large amounts of active ingredient, are related in part to the volume of solutions required for ajob. For example, onegallon of an IBA or NAA solution can be used to treat thousands of cuttings, whereas one gallon of daminozide may be sufficient to treat only a few hundred plants. Moreover, some propagators even refriger-

Table 2. Estimated U.S. regional use of chemical plant growth regulators in the greenhouse and nursery industry in 1993.

\begin{tabular}{|c|c|c|c|c|c|c|c|c|}
\hline \multirow[b]{3}{*}{ Plant growth regulator } & \multicolumn{4}{|c|}{ No. of respondents ${ }^{2}$} & \multicolumn{4}{|c|}{ 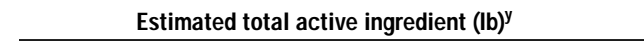 } \\
\hline & \multicolumn{8}{|c|}{ Region } \\
\hline & Northeastern & Southeastern & North-central & Western & Northeastern & Southeastern & North-central & Western \\
\hline Indolebutyric acid (IBA) & 72 & 128 & 93 & 80 & 20 & 308 & 27 & 155 \\
\hline Daminozide & 19 & 42 & 44 & 34 & 532 & 4108 & 2149 & 10889 \\
\hline Chlormequat chloride & 21 & 32 & 44 & 25 & 297 & 5221 & 782 & 1736 \\
\hline Ancymidol & 14 & 19 & 25 & 13 & $<1$ & 3 & $<1$ & 4 \\
\hline Gibberellic acid & 5 & 16 & 22 & 15 & $<1$ & 33 & 10 & 48 \\
\hline Napthal eneacetic acid & 26 & 56 & 39 & 46 & 9 & 158 & 12 & 77 \\
\hline Paclobutrazol & 14 & 24 & 17 & 12 & 8 & 14 & 3 & 4 \\
\hline Ethephon & 9 & 11 & 25 & 10 & 348 & 272 & 269 & 440 \\
\hline Uniconazole & 7 & 14 & 8 & 3 & $<1$ & 8 & $<1$ & $<1$ \\
\hline Dikegulac & 2 & 8 & 4 & 11 & 29 & 81 & 44 & 5115 \\
\hline Other & 3 & 7 & 7 & 0 & 7 & 27 & 4 & $<1$ \\
\hline
\end{tabular}

The number of responses summed across regions may not agree with figures in Table 1 because some respondents omitted data about their region.

Table 3. Reported use of chemical plant growth regulators for 1993 in the United States greenhouse and nursery industry by firm sizez.

\begin{tabular}{|c|c|c|c|c|c|c|}
\hline \multirow[b]{2}{*}{ Plant growth regulator } & \multicolumn{2}{|c|}{ Small } & \multicolumn{2}{|c|}{ Medium } & \multicolumn{2}{|c|}{ Large } \\
\hline & Active ingredient (lb) & $\%^{2}$ & Active ingredient (lb) & $\%$ & Active ingredient (lb) & $\%$ \\
\hline Indolebutyric acid (IBA) & 11.7 & 9 & 12.7 & 9 & 115.0 & 82 \\
\hline Daminozide & 95.3 & 2 & 905.4 & 18 & 4002.0 & 80 \\
\hline Chlormequat chloride & 82.2 & 4 & 1218.3 & 54 & 968.0 & 42 \\
\hline Ancymidol & 0.2 & 9 & 0.3 & 13 & 1.8 & 78 \\
\hline Gibberellic acid & 3.1 & 12 & 11.5 & 44 & 11.4 & 44 \\
\hline Naphthaleneacetic acid & 5.5 & 8 & 5.7 & 8 & 58.4 & 84 \\
\hline Paclobutrazol & 0.1 & 1 & 1.5 & 18 & 6.6 & 81 \\
\hline Ethephon & 19.5 & 5 & 102.0 & 26 & 267.6 & 69 \\
\hline Uniconazole & 0 & 0 & 2.0 & 95 & 0.1 & 5 \\
\hline Dikegulac & 15.4 & 1 & 40.1 & 3 & 1311.8 & 96 \\
\hline Other & 0.6 & $<1$ & 2.3 & 24 & 7.4 & 76 \\
\hline
\end{tabular}

zFirm size based on 1993 sales: small ( $\$ 0-\$ 500,000)$; medium ( $\$ 500,001-\$ 2,000,000)$; large $(>\$ 2,000,000)$.

yPounds of active ingredient for a plant growth regulator, used within a firm size, expressed as the percentage of the total pounds for that plant growth regulator. 
Table 4. Experience with alternatives to chemical plant growth regulators (PGRs) in the U.S. greenhouse and nursery industry in 1993.

\begin{tabular}{|c|c|c|c|c|c|c|}
\hline \multirow[b]{2}{*}{ PGR alternative } & \multicolumn{2}{|c|}{ Respondents $^{2}$} & \multicolumn{4}{|c|}{ Rating of PGR alternative (\% response) } \\
\hline & No. & $\%^{y}$ & Not effective & Somewhat effective & Very effective & Effective but impractical \\
\hline Pruning/pinching & 499 & 82 & 1 & 32 & 64 & 3 \\
\hline Withholding water & 304 & 52 & 7 & 64 & 24 & 5 \\
\hline DIF (day vs. night temperature) & 188 & 32 & 6 & 40 & 45 & 9 \\
\hline Regulating photoperiod & 170 & 29 & 6 & 47 & 40 & 7 \\
\hline Regulating light quality & 169 & 29 & 7 & 53 & 32 & 8 \\
\hline Mechanical brushing & 68 & 12 & 16 & 43 & 25 & 16 \\
\hline
\end{tabular}

2Respondents were queried as to whether or not they have used a particular plant growth regulator alternative and, if so, rate its effectiveness; 578-606 (depending on the alternative) of the 712 total respondents provided data for this question.

'Percent based on the actual number of respondents for the particular plant growth regulator alternative.

aterooting solutions for later use. Efficacy of thePGR and the amount of time the PGR has been on the market also may havebeen influential. For example, paclobutrazol is much more efficacious than daminozide, but daminozide has been on the market longer and is firmly entrenched in the industry.

The number of times PGRs were used varied in different regions of the country $\left(\chi^{2}=54.76, \mathrm{df}=\right.$ $36, P=0.023)$ (Table 2). More significant was the fact that there were 5 to 16 times less estimated total pounds of PGRs used in the northeastern region compared to other regions, even though there were about the same number of respondents as in the western region, and only $50 \%$ fewer respondents than in the southeastern or northcentral regions. This was not surprising, as there is not a demand for growth retardants for nursery crops grown in this relatively cool climate and shorter growing season, the region is not a major source for rooted-liner production, and there is less need (rate and frequency) for growth retardants for greenhouse crops. Also it is economical to control plant height of greenhouse crops grown in cooler climates by manipulating the difference between day and night temperatures, a practice commonly referred to as DIF (Heins and Erwin, 1990). Therelativeestimated total pounds of daminozideandchlormequat chloride used in the different regions seems to coincide primarily with the size of the floricultural crop industry (poinsettias, florist azaleas, mums, bedding plants, hibiscus, etc.) in those regions. The greatest use of PGRs in terms of frequency and total pounds was in the western region, wherethereis major production of nursery and floricultural crops in California, Oregon, and Washington. Growers in this region were estimated to have used over twice as much daminozide and over 63 times more dikegulac than any other region. Chlormequat chloride, widely used on poinsettias as well as greenhouse azal eas and hibiscus, not surprisingly was used most in the southeastern region, where higher rates or repeat applications may benecessary dueto higher temperatures and a longer growing season. High temperatures al so could havelead to a reduction in the use of DIF, especially in the lower south, thereby leading to the relatively high use of daminozide and chlormequat chloride in that region.

Indolebutyric acid was the most widely used PGR in all regions; however, the greatest use in terms of pounds activeingredient was in the southeastern region, a major region of propagation for nursery and greenhouse crops. The other major active ingredient used to stimulate rooting, NAA, was used less frequently, but like IBA was used most (frequency and total pounds) in the southeastern region.

The frequency of firms using PGRs was influenced by thesize of the firm $\left(\chi^{2}=65.1, \mathrm{df}=24\right.$, $P<0.001$ ), medium and large firms using the bulk of the total pounds of PGRs (Table 3 ). This is not surprising, because large firms are producing the largest crops. Moreover, therewas no reported use of uniconazole, benzylaminopurine, or the potassium salt of IBA by small firms. Daminozide and chlormequat chloride represented $73 \%$ to $92 \%$ of PGR use by all firms. These products are used on major greenhouse crops, have a relatively high degree of safety, and have become firmly entrenched in thegreenhouseindustry. Therelatively high use of dikegulac by large firms $(1311.8 \mathrm{lb})$ $(596 \mathrm{~kg})$ was by those in the western region. Of the total pounds dikegulac reported by the respondents nationwide $(5269 \mathrm{lb})(501 \mathrm{~kg})$, the combined use reported for the northeastern, southeastern, and north-central regions was less than $4 \%$ of the nationwide use.

Alternatives to chemical plant growth regulators. Pruning/pinching was used by the greatest number of respondents (499 of 606 respondents) and was the only alternative to PGRs rated as very effective by more than $60 \%$ of the respondents (Table 4). Forty-three percent of the respondents withheld water as an alternative, but only $24 \%$ found it to be a very effective practice. Conversely, about $25 \%$ of the respondents used DIF, regulated photoperiod, or regulated light quality, and $45 \%$ (DIF), $40 \%$ (photoperiod), or $32 \%$ (light quality) reported that these were very effective practices. Mechanical brushing was used by only $10 \%$ of the respondents. Sixteen percent of those who used it found it ineffective, whereas another $16 \%$ rated it as effective but impractical. The responses to use and efficacy of mechanical brushing may be because it is a relatively new practiceand factors which affect the success of this practice have not been studied thoroughly. None of the other practices were rated as ineffective or effective but impractical by more than $9 \%$ of the respondents. Other alternatives reported by one or two respondents included fertilization (5 respondents), transplanting (1), undercutting (2), special pots (1), and use of new varieties which were naturally shorter (1).

Frequency of use of aspecific al ternativeand its relative effectivenessfollowed thenational trends and were generally similar across regions with only afew exceptions(Table5). Mechanical brush-

Table 5. United States regional use of alternatives to plant growth regulators (PGRs) in the greenhouse and nursery industry in 1993.

\begin{tabular}{|c|c|c|c|c|}
\hline \multirow[b]{2}{*}{ PGR alternative } & \multicolumn{4}{|c|}{ Region $^{2}(\%$ response) } \\
\hline & Northeastern & Southeastern & North-central & Western \\
\hline Pruning/pinching & 83 & 83 & 81 & 82 \\
\hline Withholding water & 48 & 51 & 51 & 59 \\
\hline Regulating light quality & 30 & 31 & 24 & 34 \\
\hline DIF (day vs. night temperature) & 29 & 28 & 35 & 35 \\
\hline Regulating photoperiod & 27 & 30 & 31 & 30 \\
\hline Mechanical brushing & 6 & 12 & 12 & 18 \\
\hline
\end{tabular}


Table 6. Experience with alternatives to chemical plant growth regulators (PGRs) in the United States greenhouse and nursery industry in 1993 by firm sizez.

\begin{tabular}{|c|c|c|c|c|c|c|c|c|c|c|c|c|c|c|c|}
\hline \multirow[b]{4}{*}{ PGR alternative } & \multirow[b]{4}{*}{ Small } & \multirow[b]{4}{*}{ Medium } & \multicolumn{13}{|c|}{ Effectiveness rating (\% response) } \\
\hline & & & \multicolumn{4}{|c|}{ Not effective } & \multicolumn{3}{|c|}{ Somewhat effective } & \multicolumn{3}{|c|}{ Very effective } & \multicolumn{3}{|c|}{ Effective but impractical } \\
\hline & & & \multicolumn{13}{|c|}{ Firm size } \\
\hline & & & Large & Small & Medium & Large & Small & Medium & Large & Small & Medium & Large & Small & Medium & Large \\
\hline Pruning/pinching & 78 & 85 & 85 & $<1$ & 1 & 2 & 29 & 37 & 31 & 69 & 59 & 64 & 2 & 3 & 3 \\
\hline Withholding water & 36 & 56 & 71 & 8 & 6 & 7 & 61 & 63 & 66 & 25 & 29 & 19 & 6 & 2 & 7 \\
\hline DIF (day vs. night temperature) & 21 & 35 & 45 & 0 & 10 & 7 & 47 & 43 & 34 & 45 & 40 & 49 & 8 & 7 & 10 \\
\hline Regulating photoperiod & 17 & 30 & 46 & 3 & 7 & 7 & 55 & 43 & 45 & 34 & 40 & 44 & 8 & 10 & 4 \\
\hline Regulating light quality & 21 & 31 & 40 & 4 & 10 & 7 & 57 & 57 & 43 & 32 & 23 & 42 & 6 & 10 & 8 \\
\hline Mechanical brushing & 8 & 13 & 15 & 6 & 11 & 30 & 61 & 48 & 22 & 28 & 22 & 26 & 6 & 18 & 22 \\
\hline
\end{tabular}

${ }^{2}$ Respondents were queried as to whether or not they have used a particular PGR alternative and, if so, to rate its effectiveness; depending on the alternative, 218-234 small firms, 198-205 medium-sized firms, and 150-158 large firms of the 712 total respondents provided data for this question.

'yize of firm based on 1993 sales; small $(\$ 0-\$ 500,000)$, medium $(\$ 500,001-\$ 2,000,000)$, and large $(>\$ 2,000,000)$.

ing was used least in the northeastern region and most in the western region, but $29 \%$ of the users in both regions found it effective. However, $38 \%$ of those that used mechanical brushing in the western region found it ineffective, whereas in the northeastern region none found it ineffective or effective but impractical.

Firm size resulted in somedistinct trends with regards to use of PGR alternatives. Use by medium firms closely mirrored the national trends; largeand small firms reported greater or lesser use, respectively (Table 6). The direct relationship of using alternatives and firm sizewas probably areflection of the greater capital and personnel available to the largefirms, sinceeach of themethods requires some initial equipment investment or is costly in terms of labor. The effectiveness rating was influenced by firm size and the particular PGR alternative. However, $87 \%$ to $89 \%$ of all respondents who used alternatives rated them (except mechanical brushing) as a whole as somewhat to very effective (Table 6). The number of respondents who found DIF and mechanical brushing somewhat to very effective decreased with increasing firm size; mechanical brushing exhibited the sharpest decline. Thirty percent of the large-firm respondents found it ineffective and $22 \%$ of them found it effective but impractical; only $6 \%$ of the small-firm respondents reported similar ratings.

\section{Conclusions}

Therelative amounts of chemical PGRs used by the nursery and greenhouse industry in 1993 were similar to that reported by SRI (SRI International, 1992) for PGRuse in 1991. Daminozide (BNine SP) and chlormequat chloride (Cycocel) accounted for the greatest use in terms of total pounds active ingredient in both studies; rooting compounds like IBA (Dip 'N Grow, Rootone, and Hormoroot) and NAA (Dip 'N Grow, and Hormodin I, II, and III) accounted for less than $3 \%$ of total pounds in our study and $<0.2 \%$ of total pounds in SRI's 1991 survey. However, there was substantially less use of daminozide reported in 1993 than in 1991 ( $54 \%$ vs. $76 \%$ of total pounds a.i.).
Differences in those responding to each survey could account for some of the discrepancy, but some of the decline was probably due to one or more of the following developments: price increases (resulting from a ban on Alar); increased market share of new products like paclobutrazol (Bonzi) resulting from university and industry recommendations; and increased use of alternative means of growth regulation practices like DIF.

Use of chemical PGRs and nonchemical alternative practices was influenced by region and/or firm size. In the northeastern region, growers reported relatively low use of PGRs (frequency and total pounds) and reported the lowest use of mechanical brushing as an alternative practice. In contrast, mechanical brushing was used most in the western region. Largefirms (morethan $\$ 2$ million in 1993 sales) in the western region used most of the dikegulac nationwide. Large firms in general reported the greatest use of PGRs as well as alternative means of growth regulation. This seems to reflect the ability of large firms to commit the resources necessary for determining the most cost effective and safest methods for crop production.

\section{Implications for university research and extension programs}

There is a need to expand research and extension efforts in thearea of nonchemical al ternatives to PGRs despitetheir effectiveness in crop production. That fact that PGRs comprise only a minor portion of overall pesticide use in the greenhouse and nursery industry increases the likelihood of these chemicals being lost simply for economic reasons. The drive towards sustainableagriculture necessitates that we seek alternatives to chemical inputs. Also, costs associated with complying with pesticide regulations may increase to the point that it will not be economical to use some PGRs.

Significant potential exists for expanding research and extension programs directed towards nonchemical alternatives to PGRs, since the only widely reported nonchemical alternatives used was pruning/pinching. Other alternatives need to be studied in moredepth so that they can be refined and to determine why less than $50 \%$ of growers did not ratethem as very effective. An areain which substantially greater research and extension efforts need to be directed is the development and introduction of naturally shorter varieties. Only onegrower reported using this method as an alternative to PGRs. Also, propagation research using commercial formulations of rooting compounds needs to be expanded since growers no longer can purchase the technical grade of rooting chemicals.

Faculty should consider initially targeting large firms in their research and extension programs because this would seem to have the greatest initial impact. Large firms were the greatest consumers of chemical growth regulators, but also used nonchemical alternatives more than small or medium firms. Largefirms generally have more resources available for investing in new practices. Multidisciplinary approaches should be considered as well to determine the effects of nonchemical methods of growth regulation on other aspects of production such as irrigation, fertilization, and pest management.

\section{Literature Cited}

Cathy, H.M. 1964. Physiology of growth retarding chemicals. Annu. Rev. Plant Physiol. 15:271-302.

Garber, M.P., W.G. Hudson, J.G. Norcini, R.K. Jones, A.R. Chase, and K. Bondari. 1996. Pest management in the United States greenhouse and nursery industry: I. Trends in chemical and nonchemical control. HortTechnology 6:192-198.

Heins, R. and J. Erwin. 1990. Understanding and applying DIF. Greenhouse Grower 8(2):73-78.

Laurie, A. and L.C. Chadwick. 1931. The modern nursery: Aguide to plant propagation, culture, and handling. MacMillan and Co., New York.

SRI International. 1992. U.S. nursery and greenhouse ornamentals markets for pesticides. Menlo Park, Calif. 